\title{
Biochar application to detoxification of the heavy metal-contaminated fluvisols
}

\author{
Tatiana Bauer $^{1, *}$, Tatiana Minkina ${ }^{2}$, Saglara Mandzhieva ${ }^{2}$, Marina Burachevskaya $^{2}$, and \\ Maria Zharkova ${ }^{3}$ \\ ${ }^{1}$ Federal Research Center the Southern Scientific Center of the Russian Academy of Sciences, 41, st. \\ Chehova, 344006, Rostov-on-Don, Russia \\ ${ }^{2}$ Southern Federal University, 194/1, prosp. Stachki, 344090, Rostov-on-Don, Russia \\ ${ }^{3}$ Don State Technical University, 1, Sq. Gagarina, 344003, Rostov-on-Don, Russia
}

\begin{abstract}
Sorption of heavy metals on solid matrices such as soils is one of the key processes which determine the fate of contaminants in the environment. Knowledge of adsorption behavior of heavy metals using biochar is essential for their application in soil remediation. Using the adsorption method, the possibility of using a wood biochar to detoxify Fluvisols contaminated with heavy metals (for example, copper) was studied. It is shown that the addition of biochar increases the metal adsorption capacity of soil. The results were analysed using the Langmuir and Freindlich isotherm equations. It was concluded that biocar can be applied to immobilize heavy metals in contaminated soils.
\end{abstract}

\section{Introduction}

Intensification of the technogenic pollution of soil calls for scrutinization of the behavior of contaminants, heavy metals included. Sorption is the main process responsible for the behavior of heavy metals in soil, since mobility and toxicity of metals correlate directly with their distribution between the solid and liquid phases therein. The sorption capacity of soil is influenced by $\mathrm{pH}$ values and the presence of active adsorption centers in different soil components, such as carbonates, phosphates, organic matter, silicates, and (hydr)oxides [1].

Development of ecological methods to detoxify the heavy metal-contaminated soil using natural sorbents is a promising research direction. Natural carbonaceous sorbents are actively applied to remediate the polluted soil such as biochar [2, 3, 4]. Their addition influences chemical properties of the soil, such as $\mathrm{pH}$, cation exchange capacity, feedstock characteristics [5] and, consequently, efficiency of metal sorption [6]. Sorption in microand mesopores, as well as specific interaction with the surface functional groups (particularly, oxygen-containing donor ligands, such as carboxylates) of carbonaceous sorbents, play an important role in the soil fertility $[6,7]$.

Assessment of the sorption of pollutants by soil is based usually on laboratory experiments with a quantitative estimation of the coefficient of metal distribution between the solid and liquid phases therein. Among several (empirical/mechanistic) models

*Corresponding author: bauertatyana@mail.ru 
proposed to define the sorptional metal distribution in soil, the Langmuir and Freindlich models are most common [8].

In this connection, assessment of the adsorption of heavy metal ions by soil in the presence of a carbonaceous sorbent is of particular interest. Due to their large specific surface area (SSA), rich porous structure, and high adsorption capacity, carbonaceous adsorbents have been widely used in inorganic pollutant sorption [9]. Studies of the detoxification of $\mathrm{Cu}$-contaminated soil are particularly important. High technical applicability of copper and its extensive use in different industrial fields are responsible for the soil pollution with this metal.

\section{Materials and Methods}

We studied Fluvisols (layer 0-20 cm) sampled from the Severskii Donets River floodplain (Kamensk-Shakhta district, Rostov region). This soil is characterized by the following physical and chemical properties: $\mathrm{pH} 7.5$, Corg $0.9 \%$, exchange cations $\left(\mathrm{Ca}^{2+}+\mathrm{Mg}^{2+}\right) 6.6$ $\mathrm{cM}(+) / \mathrm{kg}, \mathrm{CaCO}_{3} 0.1 \%$, physical clay $2.8 \%$, and silt $1.6 \%$. The soil was doped with a carbonaceous sorbent $\left(2.5 \mathrm{wt} \%\right.$ approximately corresponding to $500 \mathrm{~kg} / 100 \mathrm{~m}^{2}$ or $50 \mathrm{t} / \mathrm{ha}$ if recalculated to the 20 -cm-thick topsoil).

The sorbent was represented by biochar obtained from the pyrolysis of birch wood on a rotary retort (grade A, quality 1 , pyrolysis temperature $550^{\circ} \mathrm{C}$, biochar fraction $3-5 \mathrm{~mm}$ ). The specific surface and porosity of the carbon-bearing samples were measured with an ASAP 2020 volumetric analyser, and micromeritic properties were determined by the lowtemperature nitrogen adsorption method. The specific surface and porosity parameters were determined using the $\mathrm{N}_{2}$-based BET specification method in the equilibrium range of $\mathrm{P} / \mathrm{P} 0$ $=0.05-0.97$. Volumes of micro- and mesopores in the sorbents were determined with the relative $t$ method based on the Hurkins-Jura equation for computing thickness of the statistic adsorbate layer [10]. Computation of the pore size distribution was based on the nonlocal density functional theory [11]. Measurement of the specific surface yielded the following values: specific surface $540 \mathrm{~m}^{2} / \mathrm{g}$, total pore volume $0.81 \mathrm{~cm}^{3} / \mathrm{g}$. According to the data obtained biochar can be categorized as microporous coals with a small content of mesopores $\left(0.04 \mathrm{~cm}^{3} / \mathrm{g}\right)$, and a large number of micropores $\left(0.63 \mathrm{~cm}^{3} / \mathrm{g}\right)$.

The total contents of $\mathrm{C}, \mathrm{H}$ and $\mathrm{N}$ in the carbonaceous sorbents were determined using a CHN elemental analyzer (TOC-L CPN Shimadzu, Japan). Ash content was measured by heating sorbents at $650{ }^{\circ} \mathrm{C}$ for $3 \mathrm{~h}$ and $\mathrm{O}$ content was calculated by mass difference. Molar ratios of elements, often used to estimate the aromaticity $(\mathrm{H} / \mathrm{C}$ ratio) and polarity $(\mathrm{O} / \mathrm{C},(\mathrm{O}$ $+\mathrm{N}) / \mathrm{C}$ are also provided in Table 1 .

Table 1. Elemental composition of biochar.

\begin{tabular}{|c|c|c|c|c|c|c|c|}
\hline C & $\mathbf{N}$ & H & O & Ash & \multirow{2}{*}{$\mathrm{H} / \mathrm{C}$} & \multirow{2}{*}{$\mathrm{O} / \mathrm{C}$} & \multirow{2}{*}{$(\mathrm{N}+\mathrm{O}) / \mathrm{C}$} \\
\hline \multicolumn{5}{|c|}{$\%$} & & & \\
\hline 74.3 & 2.3 & 2.7 & 12.9 & 7.8 & 0.43 & 0.13 & 0.16 \\
\hline
\end{tabular}

Air-dried aliquots $(5 \mathrm{~g})$ of the studied samples were flushed with $50 \mathrm{ml}$ of $\mathrm{Cu}\left(\mathrm{NO}_{3}\right)_{2}$ solutions with the following $\mathrm{Cu}^{2+}$ concentrations $\left(\mathrm{mM} \cdot 1^{-1}\right): 0.05,0.08,0.1,0.3,0.5,0.8$, and 1.0. The metal solutions were prepared from $\mathrm{Cu}\left(\mathrm{NO}_{3}\right)_{2} \times 3 \mathrm{H}_{2} \mathrm{O}$ salt of the 'chemically pure' grade.

Suspensions were stirred for $1 \mathrm{~h}$, left in the calm state for $24 \mathrm{~h}$, then centrifuged and filtered. The metal content in filtrates was determined by the atomic adsorption spectrometry with electrothermic atomization and polarization Zeeman effect correction for the nonselective adsorption using an MGA-915MD spectrometer (Lumex ScientificProduction Company, St. Petersburg). The amount of metal absorbed by the solid phase 
was deduced from the difference between the added amount and the concentration measured in the equilibrium solution:

$$
\mathrm{C}_{a d}=\frac{\left(\mathrm{C}_{i}-\mathrm{C}_{S}\right) \cdot V}{m}
$$

where $\mathrm{C}_{\mathrm{ad}}$ is the amount of metal adsorbed by a unit sorbent mass, $\mathrm{mM} \cdot \mathrm{kg}^{-1} ; \mathrm{C}_{\mathrm{i}}$ is the initial metal concentration in solution, $\mathrm{mM} \cdot \mathrm{l}^{-1} ; \mathrm{C}_{\mathrm{s}}$ is the equilibrium metal concentration in solution, $\mathrm{mM} \cdot{ }^{-1} ; \mathrm{V}$ is the solution volume, $\mathrm{cm}^{3}$; and $\mathrm{m}$ is the air-dry sorbent mass, $\mathrm{g}$.

The obtained data were used to draw the $\mathrm{C}_{\mathrm{s}}-\mathrm{C}_{\mathrm{ad}}$ plot, where $\mathrm{C}_{\mathrm{s}}$ is the equilibrium concentration of metal added to the solution, $\mathrm{mM} \cdot \mathrm{l}^{-1}$; and $\mathrm{C}_{\mathrm{ad}}$ is the specific content of metal in the sorbent phase, $\mathrm{mM} \cdot \mathrm{kg}^{-1}$.

Coefficients of metal distribution between the solid and liquid phases $\left(\mathrm{K}_{\mathrm{d}}\right)$ and the sorption degree (S) were computed according to formulas:

$$
\begin{aligned}
& K_{d}=\frac{\left(\mathrm{C}_{i}-\mathrm{C}_{S}\right) \cdot V}{C_{s} \cdot m}, \\
& S=\frac{C_{i}-\mathrm{C}_{S}}{\mathrm{C}_{S}} \cdot 100 \%,
\end{aligned}
$$

where $\mathrm{C}_{\mathrm{i}}$ and $\mathrm{C}_{\mathrm{s}}$ are, respectively, the initial and equilibrium metal concentration in solution, $\mathrm{mM} \cdot \mathrm{l}^{-1} ; \mathrm{V}$ is the solution volume, $\mathrm{cm}^{3}$; and $\mathrm{m}$ is the sorbent aliquot, $\mathrm{g}$.

The results were statistically processed using the SigmaPlot 12.5 and Excel software packages with confidence coefficient of 0.95 . Each experimental isotherm point was fixed after three replications.

\section{Results and Discussion}

Table 2 presents the computed values of $\mathrm{Kd}$ and the degree of $\mathrm{Cu}^{2+}$ ion sorption (S) by Fluvisols in the pure state and after the biochar addition. In solutions with the initial metal concentration up to $0.5 \mathrm{mM} \cdot{ }^{-1}$, the degree of $\mathrm{Cu}^{2+}$ extraction by soil is almost $98 \%$. In solutions with the initial $\mathrm{Cu}$ (II) concentration of $1.0 \mathrm{mM} \cdot \mathrm{l}^{-1}$, the degree of metal ion extraction falls to $96 \%$ after the sorptional interaction with soil. In versions with the biochar addition to soil in the studied concentration range, the metal adsorption is close to $100 \%$ (Table 2).

All studied samples display an appreciable inverse correlation of $\mathrm{Cd}$ with the $\mathrm{Cu}$ concentration in the initial and, correspondingly, equilibrium solution, suggesting a decrease in the share of the sorbent-absorbed metal and the energy of ion interaction with the sorbent-surface functional groups that govern their adsorption capacity. The decrease in adsorption capacity can be attributed to the presence of several types of sorption centers on the surface of soil particles that differ not only in affinity, but also in selectivity to different cations, $\mathrm{Cu}$ included [12]. It is noteworthy that the sorbent addition to soil is reflected strongly upon the metal distribution coefficient $\left(\mathrm{K}_{\mathrm{d}}\right)$, which is 5-11 times higher in the case of biochar addition (Table 1). This discrepancy can be explained based on the soil phases and metal parameters that regulate the adsorption. The adsorption of $\mathrm{Cu}$ is controlled by the content of organic matter in soils, mineral varieties included [13]. Addition of highcarbonaceous sorbents to the soil increases the content of organic carbon and, correspondingly, sorption active centers relative to metal. Ion of $\mathrm{Cu}$ (II) penetrates into micropores in the carbonaceous sorbent due to its small radius $(0.072 \mathrm{~nm})$ [14] and interacts with the electrostatic field of the sorbent matrix. Electrostatic attraction between the positively charged $\mathrm{Cu}^{2+}$ ions and the negatively charged biochar surface is the prevalent mechanism of $\mathrm{Cu}$ immobilization in soils [15]. 
Table 2. Distribution coefficient $(\mathrm{Cd})$ and sorption degree (S) of $\mathrm{Cu}^{2+}$ ions by Fluvisols in the presence of biochar.

\begin{tabular}{|c|c|c|c|c|c|c|c|}
\hline \multirow{2}{*}{ Sample } & \multicolumn{7}{|c|}{ Metal concentration in the initial solution, mM· $\mathbf{- 1}^{-1}$} \\
\cline { 2 - 8 } & $\mathbf{0 . 0 5}$ & $\mathbf{0 . 0 8}$ & $\mathbf{0 . 1}$ & $\mathbf{0 . 3}$ & $\mathbf{0 . 5}$ & $\mathbf{0 . 8}$ & $\mathbf{1 . 0}$ \\
\hline \multicolumn{8}{|c|}{$C_{\mathrm{d}}, 1 \cdot \mathrm{kg}^{-1}$} \\
\hline Soil & 546 & 724 & 784 & 642 & 506 & 333 & 241 \\
\hline Soil+biochar & 6240 & 7263 & 5253 & 3181 & 2622 & 2276 & 1714 \\
\hline \multicolumn{8}{|c|}{$\mathrm{S}, \%$} \\
\hline Soil & 98.20 & 98.64 & 98.74 & 98.47 & 98.06 & 97.09 & 96.02 \\
\hline Soil+biochar & 99.84 & 99.86 & 99.81 & 99.69 & 99.62 & 99.56 & 99.42 \\
\hline
\end{tabular}

Isotherms of $\mathrm{Cu}^{2+}$ adsorption separately by soil and during the addition of carbonaceous sorbents are presented in Fig. 1. Experimental data are approximated based on the Langmuir (4) and Freindlich equations (5):

$$
\begin{gathered}
\mathrm{C}_{\mathrm{ad}}=\mathrm{C}_{\infty} \mathrm{K}_{\mathrm{L}} \mathrm{C}_{\mathrm{s}} /\left(1+\mathrm{K}_{\mathrm{L}} \mathrm{C}_{\mathrm{s}}\right), \\
\mathrm{C}_{\mathrm{ad}}=\mathrm{KF} \cdot \mathrm{C}_{\mathrm{s}}{ }^{\mathrm{n}},
\end{gathered}
$$

where $\mathrm{C}_{\mathrm{ad}}$ is the concentration of adsorbed cations, $\mathrm{mM} \cdot \mathrm{kg}^{-1}$ soil; $\mathrm{C}_{\infty}$ is the maximum metal adsorption; $\mathrm{C}_{\mathrm{s}}$. is the metal concentration in equilibrium solution, $\mathrm{mM} \cdot \mathrm{l}^{-1} ; \mathrm{K}_{\mathrm{L}}$ and $\mathrm{K}_{\mathrm{F}}$ are the Langmuir and Freindlich constants, respectively; and $\mathrm{n}$ is the empirical exponent in the Freindlich equation. Value of $n$ characterises the degree of isotherm approximation to a straight line (Henry zone). It can be considered an indicator of the heterogeneity of sorption centers: $n$ approaches 0 with the increase of heterogeneity and tends to 1 with the increase of homogeneity [16].

The Langmuir model is based on three main suppositions: all adsorption sites on the sorbent surface are energy equivalent; sorption occurs in some places and interaction between the sorbed ions is lacking. Sorption is characterised by multilayer pattern, and it reaches the maximum when the monolayer is completely filled up. The Freindlich model assumes that first of all sorption centers with a stronger binding capacity are filled up and the bond strength shows inverse correlation with the filling degree. In contrast to the Langmuir equation, the Freindlich isotherm does not yield the limit value of metal adsorption during saturation [17]. Isotherms of $\mathrm{Cu}^{2+}$ adsorption by the studied samples show a linear zone at low metal concentrations in the solution and another zone tending to saturation at high concentrations (Fig. 1). Note that the process of metal adsorption by the biochar added soil is much more intense than by the initial Fluvisols (Fig. 1). Greater copper sorption likely results as the strength of interaction mechanism evolve from cation exchange to specific interactions including coordination by the surface functional groups of carbonaceous material.

Table 3 presents the main parameters of metal adsorption by the studied samples. As is evident form the determination coefficients $\left(\mathrm{R}^{2}=0.99\right)$, experimental data on the $\mathrm{Cu}$ (II) adsorption are defined best by the Langmuir model. Approximation of the experimental isotherms based on the Freindlich equation is characterized by $\mathrm{R}^{2}$ values ranging from 0.90 to 0.97 .

Constant of the adsorption equilibrium $\mathrm{K}_{\mathrm{L}}$ characterises the degree of adsorbateadsorbent affinity and serves as measure of the adsorption activity of sorbent. The higher the $\mathrm{K}_{\mathrm{L}}$ value, the stronger is the adsorbate-adsorbent interaction and the better is the metal ion adsorption from solution. Values of constant $\mathrm{K}_{\mathrm{L}}$ for the metal cation adsorption by the initial soil are 3.8 times lower than in the biochar added scenario (Table 3). 


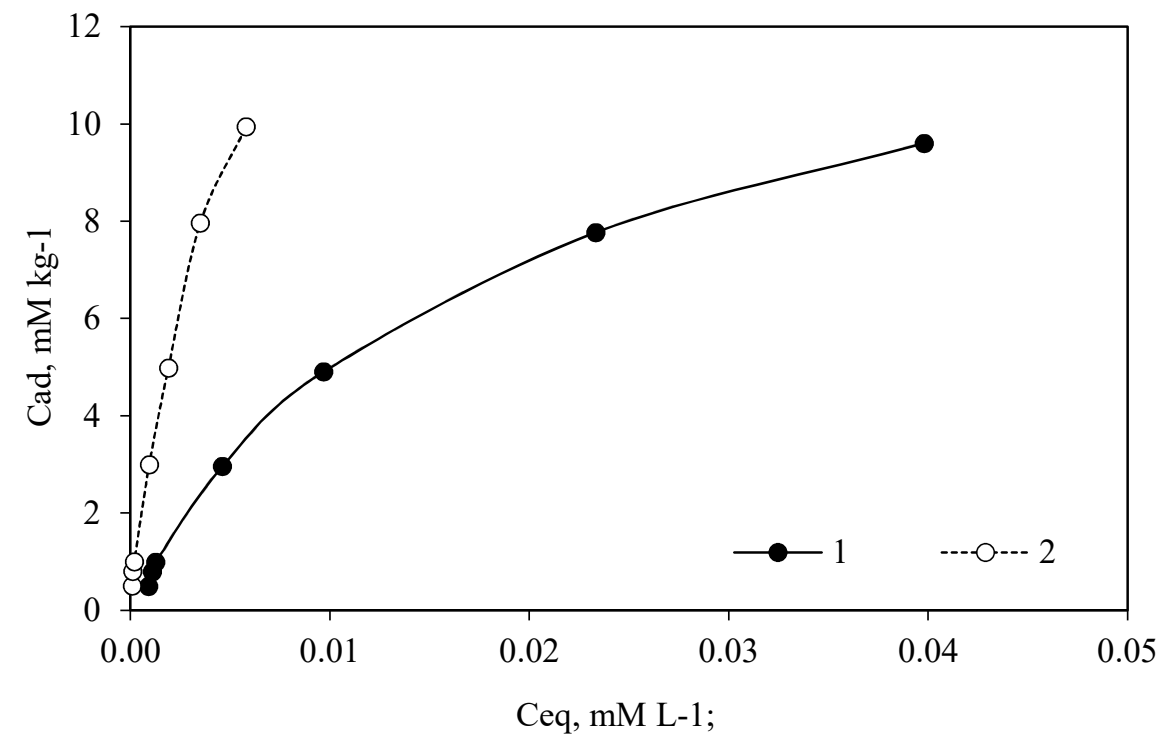

Fig. 1. Isotherms of $\mathrm{Cu}^{2+}$ ion adsorption by the initial Fluvisols (1) and the biochar added Fluvisols (2).

Values of maximum $\mathrm{Cu}^{2+}$ adsorption $\left(\mathrm{C}_{\infty}\right)$ by soil based on Eq. (4) are also higher when the biochar is added. Discrepancies in $\mathrm{C}_{\infty}$ values of metal, however, in the studied samples are insignificant relative to $\mathrm{K}_{\mathrm{L}}$ values.

Table 3. Parameters of $\mathrm{Cu}^{2+}$ ion adsorption by the studied samples.

\begin{tabular}{|c|c|c|c|c|c|c|}
\hline \multirow{2}{*}{ Sample } & \multicolumn{3}{|c|}{ Langmuir model } & \multicolumn{3}{c|}{ Freindlich model } \\
\cline { 2 - 7 } & $\mathbf{C}_{\infty}, \mathbf{m M}^{\mathbf{m}} \mathbf{k g}^{-\mathbf{1}}$ & $\mathbf{K}_{\mathbf{L}}, \mathbf{l} \cdot \mathbf{m M M}^{\mathbf{- 1}}$ & $\mathbf{R}^{\mathbf{2}}$ & $\mathbf{K}_{\mathbf{F}}, \mathbf{k g} \cdot \mathbf{l}^{\mathbf{1}}$ & $\mathbf{n}$ & $\mathbf{R}^{\mathbf{2}}$ \\
\hline Soil & $13.8 \pm 0.3$ & $57.1 \pm 3.0$ & 0.99 & $66.7 \pm 12.60$ & $0.6 \pm 0.05$ & 0.98 \\
\hline Soil+biochar & $17.9 \pm 1.7$ & $218.2 \pm 36.9$ & 0.99 & $283.2 \pm 56.5$ & $0.6 \pm 0.04$ & 0.99 \\
\hline
\end{tabular}

Parameters based on the Freindlich equation demonstrate a trend similar to the adsorption parameters computed from Eq. (4). Addition of biochar fosters the bond strength of $\mathrm{Cu}$ with soil: $\mathrm{K}_{\mathrm{F}}$ value increases 4.2 times (Table 3 ).

\section{Conclusions}

Thus, addition of wood biochar to soil enhances the sorption capacity of Fluvisols relative to $\mathrm{Cu}^{2+}$ ions due to increase of the specific surface (physical sorption related to high porosity of the carbonaceous sorbent). These results are of great importance for the environmental application of biochar for the detoxification of the heavy metalcontaminated soils.

\section{Acknowledgments}

The reported study was funded by RFBR, project number 19-34-60041 and Grant of President of Russian Federation, no. MK-2244.2020.5. 


\section{References}

1. N. Bolan, A. Kunhikrishnan, R. Thangarajan, J. Kumpiene, J. Park, T. Makino, M.B. Kirkham, K. Scheckel, J. Hazard. Mater. 266, 141-166 (2014) doi: 10.1016/j.jhazmat.2013.12.018

2. S. Bashir, M. Shaaban, S. Mehmood, J. Zhu, Q. Fu, H. Hu, Bull. Environ. Contam. Toxicol. 100, 834-838 (2018) doi: 10.1007/s00128-018-2332-6

3. A.H. Lahori, Z. Guo, Z. Zhang, R. Li, A. Mahar, M.K. Awasthi, F. Shen, T.A. Sial, F. Kumbhar, P. Wang, S. Jiang, Pedosphere 27, 991-1014 (2017) doi: 10.1016/S10020160(17)60490-9

4. J. Meng, M.M. Tao, L. Wang, X.M. Liu, J.M. Xu, Sci. Total Environ. 633, 300-307 (2018) doi:10.1016/j.scitotenv.2018.03.199

5. M. Ahmad, A.U. Rajapaksha, J.E. Lim, M. Zhang, N. Bolan, D. Mohan, M. Vithanage, S.S. Lee, Y.S. Ok, Chemosphere 99, 19-33 (2014) doi:10.1016/j.chemosphere.2013.10.071

6. M. Uchimiya, L.H. Wartelle, I.M. Lima, K.T. Klasson, J. Agric. Food. Chem. 58, 12350-12356 (2010) doi: 10.1021/jf102152q

7. S. Batool, M. Idrees, Q. Hussain, J. Kong, Chem. Phys. Lett. 689, 190-198 (2017) doi: 10.1016/j.cplett.2017.10.016

8. G. Limousin, J.P. Gaudet, L. Charlet, S. Szenknect, V. Barthe's, M. Krimissa, Appl. Geochem. 22, 249-275 (2007) doi:10.1016/j.apgeochem.2006.09.010

9. S. Wu, H. He, X. Inthapanya, C. Yang, L. Lu, G. Zeng, Z. Han, Environ. Sci. Pollut. Res. 24, 16560-16577 (2017) doi: 10.1007/s11356-017-9168-1

10. C. Scherdel, G. Reichenauer, M. Wiener, Micropor. Mesopor. Mat. 132(3), 572-575 (2010) doi: 10.1016/j.micromeso.2010.03.034

11. J. Landers, G.YuGor, A.V. Neimark, Colloids Surf A: Physicochem. Eng. Asp. 437, 3 32 (2013) doi: 10.1002/chin.201406276

12. L. Huang, Q. Jin, P. Tandon, A. Li, A. Shan, J. Du, Chemosphere 197, 411-419 (2018) doi: 10.1016/j.chemosphere.2018.01.056

13. D.L. Pinskii, T.M. Minkina, T.V. Bauer, D.G. Nevidomskaya, S.S. Mandzhieva, M.V. Burachevskaya, Geochem. Int. 56(3), 266-275 (2018) doi: 0.1134/S0016702918030072

14. L. Zhang, S. Tang, C. Jiang, X. Jiang, Y. Guan, ACS Appl. Mater. Interfaces 10, 43013-43030 (2018) doi: 10.1021/acsami.8b15049

15. M. Uchimiya, L.H. Wartelle, T. Klasson, C.A. Fortier, I.M. Lima, J. Agric. Food Chem. 59, 2501-2510 (2011) doi: 10.1021/jf104206c

16. L. Tang, G.D. Yang, G.M. Zeng, Y. Cai, S.S. Li, Y.Y. Zhou, Y. Pang, Y.Y. Liu, Y. Zhang, B. Luna, Chem. Eng. J. 239, 114-122 (2014) doi: 10.1016/j.cej.2013.10.104

17. H. Cui, J. Zhou, Y. Si, J. Mao, Q. Zhao, G. Fang, J. Liang, J. Soils Sediments 14, $1397-$ 1406 (2014) doi: 10.1007/s11368-014-0882-8 